\title{
Use of low-molecular weight heparin, transfusion and mortality in COVID-19 patients not requiring ventilation
}

\author{
Elvira Grandone ${ }^{1,2}{ }^{(1)} \cdot$ Giovanni Tiscia $^{1} \cdot$ Raffaele Pesavento $^{3} \cdot$ Antonio De Laurenzo $^{1} \cdot$ Davide Ceccato $^{3}$. \\ Maria Teresa Sartori ${ }^{3} \cdot$ Lucia Mirabella $^{4} \cdot$ Gilda Cinnella $^{4} \cdot$ Mario Mastroianno $^{5} \cdot$ Lidia Dalfino $^{6}$. Donatella Colaizzo ${ }^{1}$. \\ Roberto Vettor $^{3} \cdot$ Mariano Intrieri $^{7} \cdot$ Angelo Ostuni $^{8} \cdot$ Maurizio Margaglione $^{9} \cdot$ On behalf of CSS- COVID
}

Accepted: 13 March 2021 / Published online: 12 April 2021

(c) The Author(s), under exclusive licence to Springer Science+Business Media, LLC, part of Springer Nature 2021

\begin{abstract}
It is still debated whether prophylactic doses of low-molecular- weight heparin (LMWH) are always effective in preventing Venous Thromboembolism (VTE) and mortality in COVID-19. Furthermore, there is paucity of data for those patients not requiring ventilation. We explored mortality and the safety/efficacy profile of LMWH in a cohort of Italian patients with COVID-19 who did not undergo ventilation. From the initial cohort of 422 patients, 264 were enrolled. Most ( $\mathrm{n}=156,87.7 \%)$ received standard LMWH prophylaxis during hospitalization, with no significant difference between medical wards and Intensive Care Unit (ICU). Major or not major but clinically relevant hemorrhages were recorded in 13 (4.9\%) patients: twelve in those taking prophylactic LMWH and one in a patient taking oral anticoagulants (p: n.s.). Thirty-nine patients (14.8\%) with median age 75 years. were transfused. Hemoglobin $(\mathrm{Hb})$ at admission was significantly lower in transfused patients and $\mathrm{Hb}$ at admission inversely correlated with the number of red blood cells units transfused $(p<0.001)$. In-hospital mortality occurred in 76 (28.8\%) patients, 46 (24.3\%) of whom admitted to medical wards. Furthermore, Hb levels at admittance were significantly lower in fatalities (g/dl 12.3; IQR 2.4 vs. 13.3; IQR 2.8; Mann-Whitney U-test; $p=0.001)$. After the exclusion of patients treated by LMWH intermediate or therapeutic doses $(n=32)$, the logistic regression showed that prophylaxis significantly and independently reduced mortality (OR 0.31, 95\% CI 0.13-0.85). Present data show that COVID-19 patients who do not require ventilation benefit from prophylactic doses of LMWH.
\end{abstract}

Keywords COVID-19 $\cdot$ Ventilation $\cdot$ Low-molecular-weight heparin $\cdot$ Mortality

\section{Highlights}

- It is uncertain whether prophylactic doses of low-molecular- weight heparin are always effective in preventing mortality in COVID-19

Elvira Grandone

e.grandone@operapadrepio.it

1 Thrombosis and Haemostasis Unit, Fondazione I.R.C.C.S. "Casa Sollievo della Sofferenza", Viale Cappuccini, S. Giovanni Rotondo, 71013 Foggia, Italy

2 Ob/Gyn Department of The First I.M. Sechenov Moscow State Medical University, Moscow, Russia

3 Department of Internal Medicine, University of Padua, Padua, Italy

4 Department of Anesthesia and Intensive Care, University of Foggia, Foggia, Italy
- There is paucity of data for those patients not requiring ventilation

- In patients not requiring ventilation, prophylactic doses of low-molecular- weight heparin significantly and independently reduce mortality

5 Scientific Direction, Fondazione I.R.C.C.S. "Casa Sollievo Della Sofferenza”, S. Giovanni Rotondo, Foggia, Italy

6 Anesthesia and Intensive Care Unit, University of Bari, Bari, Italy

7 Department of Medicine and Health Science "V. Tiberio", University of Molise, Campobasso, Italy

8 Immunohematology and Transfusion Medicine Service, Azienda Ospedaliero-Universitaria Consorziale Policlinico di Bari, University of Bari "Aldo Moro", and Struttura Regionale Coordinamento Puglia, Bari, Italy

9 Medical Genetics, University of Foggia, Foggia, Italy 
- Although transfusion need is not higher in these patients, number of transfusions are significantly and independently associated with mortality

\section{Introduction}

COVID-19 pandemic has provoked a significantly increase of mortality worldwide [1]. Elderly and comorbid patients have a significantly higher risk of fatalities, especially during hospitalization [2].

COVID-19 patients are at higher risk of Venous Thromboembolism (VTE) [3-5]. Since the beginning of pandemic the World Health Organization has recommended antithrombotic prophylaxis with Low Molecular Weight Heparin (LMWH) to reduce the VTE risk [6]. The overall risk of VTE in COVID-19 is 21\% (95\% CI 17-26\%) and, not unexpectedly, is higher in patients admitted to Intensive Care Unit (ICU) (31\%, 95\% CI 23-39). Furthermore, pooled mortality rate is $23 \%$ among patients with and $13 \%$ among those without VTE [7].

Several observational data suggested that anticoagulation may be of benefit in these patients, either in reducing VTE rate or mortality [7-10]. However, it is still debated whether prophylactic doses of LMWH are enough to prevent VTE and mortality especially in those admitted to Intensive Care Unit (ICU). A registry of arterial and venous thromboembolic complications showed high VTE rate specially in the intensive care setting, despite a high utilization rate of thromboprophylaxis [11]. On the other hand, treatment with therapeutic doses of anticoagulants were associated with a higher bleeding rate [12-14], whereas preliminary data suggest that intermediate doses can be safe [15].

We have explored mortality in a cohort of Italian patients with COVID-19 who did not require ventilation. We assessed the safety/efficacy profile of prophylactic doses of low-molecular- weight heparin (LMWH).

\section{Patients and methods}

\section{Patients}

Outcomes of the present study were: (1) to investigate mortality in patients with COVID-19 who did not require ventilation; (2) to assess the safety/efficacy profile of LMWH at prophylactic doses.

We have previously described the initial cohort [16]. Briefly, we recruited 422 patients with a laboratory-confirmed diagnosis (i.e., RT-PCR according to the protocol established by the WHO) and radiologically confirmed pneumonia observed in four Italian academic hospitals (University hospital of Padua, Research Institute "Casa Sollievo della
Sofferenza", University hospital of Foggia and University of Bari) from 3rd March until 30th August 2020. After the exclusion of those who needed treatment with invasive or non -invasive ventilation $(n=158), 264$ patients were considered for this study.

Demographic data, comorbidities, medications, clinical variables and in-hospital mortality were obtained from medical records. The study was approved by the local Review Board and carried out in accordance with the Declaration of Helsinki.

Standard prophylactic LMWH dose was labeled as subcutaneous administration of enoxaparin $4000 \mathrm{IU}$ once daily, intermediate doses as $60 \mathrm{mg}$ once-daily or $4000 \mathrm{IU}$ twice daily and therapeutic doses as administration of $100 \mathrm{U} / \mathrm{Kg}$ twice daily.

Major bleeding was defined as (1) fatal bleeding and/or (2) symptomatic bleeding in a critical area or organ, such as intracranial, intraspinal, intraocular, retroperitoneal, intraarticular or pericardial, or intramuscular with compartment syndrome, and/or (3) bleeding causing a fall in hemoglobin level of $2 \mathrm{~g} / \mathrm{dl}(1.24 \mathrm{mmol} / \mathrm{L})$ or more, or leading to transfusion of two or more units of whole blood or red cells [17]. Non major, but clinically relevant bleed was defined as an acute or subacute clinically overt bleed that does not meet the criteria for a major bleed but prompts a clinical response, as it leads to one of the following: (1) hospital admission for bleeding, or (2) physician-guided medical or surgical treatment for bleeding, or (3) change in antithrombotic therapy (including interruption or discontinuation of study drug) [18].

\section{Statistical analysis}

Normal variables were summarized as means and standard deviations, and non-normal variables as medians and interquartile range (IQR). We used the $\chi^{2}$ test, Fisher's exact test or Mann-Whitney test to compare differences where appropriate. Multivariable logistic analysis was performed to assess the independent association of all-cause mortality with significant variables found at univariate analysis. Adjustment was made for confounders that can influence prognosis of the disease (age, sex, comorbidities, therapy with corticosteroids, antiviral agents, anticoagulants and antiplatelets, hemoglobin values at admission) or are associated with its severity [ICU admission, number of red blood cell (RBC) units]. All statistical procedures were performed using SPSS 25.0 software (SPSS Inc., Chicago, IL, USA).

\section{Results}

\section{Patient characteristics}

Demographic and clinical features of the entire cohort and by care setting are shown in Table 1 . Patients admitted to 
ICU were older and more often males compared to those admitted to medical wards.

At admission, $13.6 \%$ patients were taking oral anticoagulants, $22.3 \%$ antiplatelet drugs, whereas $1.9 \%(n=5)$ were taking both (Table 1). With regards to oral anticoagulants, 16 were taking DOACs. Overall, 87.7\% $(n=229 / 261,3$ cases missing) received standard LMWH prophylaxis during hospitalization, with no significant difference between medical wards and ICU (Table 1). Overall, 12.3\% $(n=32 / 261)$ did not receive LMWH during hospitalization, [24 (12.7\%) in ICU and $8(10.7 \%)$ in medical wards, p: n.s.]. Table 2 shows different LMWH regimens according to care setting: most of those $(n=147,77.8 \%)$ admitted to medical wards received standard prophylactic doses, 49 of whom $(33.3 \%)$ in association with antiplatelet drugs. Intermediate or therapeutic doses were mostly used in ICU patients [17/67 (25.4\%) and $15 / 162(9.3 \%)$ respectively], although prophylactic doses were by far the most used in medical wards, as well as in ICU (Table 2).

With regards to major or not major but clinically relevant hemorrhages, they were recorded in $13(4.9 \%)$ patients: twelve occurred in those taking prophylactic doses of LMWH (in one case in association with antiplatelets) and one in a patient taking oral anticoagulants (p: n.s.). Among them, only one (taking prophylactic LMWH) needed 1 RBC unit.

\section{Transfusion rates and factors associated with transfusion}

Thirty-nine patients (14.8\%) with median age 75 years (IQR 16) were transfused (Table 3 ). Overall, 38 received $\mathrm{RBC}$ units, 5 plasma and 4 platelets (one patient without RBC). Twenty-two out of 38 received 1-2 RBC units, nine received

Table 1 Demographic and clinical information of entire study population and divided by admission to hospital wards

\begin{tabular}{|c|c|c|c|c|}
\hline Variables & $\begin{array}{l}\text { All patients } \\
\mathrm{n}=264\end{array}$ & $\begin{array}{l}\text { Medical wards } \\
\mathrm{n}=189\end{array}$ & $\begin{array}{l}\mathrm{ICU} \\
\mathrm{n}=75\end{array}$ & $\mathrm{p}$ \\
\hline Sex, males & $149(56.4)$ & $98(51.9)$ & $51(68)$ & 0.017 \\
\hline Age years, median (IQR) & $72(21)$ & $73(22)$ & $70(19)$ & n.s \\
\hline Smoking, n (\%) & $21(8)$ & $15(7.9)$ & $6(8)$ & n.s \\
\hline Diabetes, n (\%) & $56(21.2)$ & $40(21.2)$ & $16(21.3)$ & n.s \\
\hline Hypertension, n (\%) & $135(51.1)$ & $99(52.4)$ & $36(48)$ & n.s \\
\hline History of cancer and/or active cancer n $(\%)$ & $44(16.7)$ & $33(17.5)$ & $11(14.7)$ & n.s \\
\hline Cerebrovascular disease, $\mathrm{n}(\%)$ & $19(7.2)$ & $10(5.3)$ & $9(12)$ & n.s \\
\hline Cardiovascular disease, $\mathrm{n}(\%)$ & $64(24.2)$ & $48(25.4)$ & $16(21.3)$ & n.s \\
\hline Chronic kidney disease, n (\%) & $34(12.9)$ & $24(12.7)$ & $10(13.3)$ & n.s \\
\hline Chronic obstructive pulmonary disease, n (\%) & $28(10.6)$ & $18(9.5)$ & $10(13.3)$ & n.s \\
\hline Major or $\mathrm{NMCR}^{\mathrm{a}}$ haemorrhage & $13(4.9)$ & $7(3.7)$ & $6(8)$ & n.s \\
\hline Transfusion & $39(14.8)$ & $19(10.1)$ & $20(26.7)$ & 0.002 \\
\hline $\mathrm{Hb}$ at admission $\mathrm{g} / \mathrm{dl}$, median (IQR) & $12.8(3.0)$ & $12.8(3.1)$ & $12.8(3.0)$ & n.s \\
\hline \multicolumn{5}{|l|}{ Anticoagulant and antiplatelets therapy } \\
\hline Anticoagulants at admission $\mathrm{n}^{\mathrm{b}}(\%)$ & $36(13.6)$ & $28(14.8)$ & $8(10.7)$ & n.s \\
\hline Antiplatelets at admission $\mathrm{n}^{\mathrm{c}}(\%)$ & $59(22.3)$ & $41(21.7)$ & $18(24)$ & n.s \\
\hline LMWH during hospitalization & $229^{\mathrm{a}}(87.7)$ & $162^{\mathrm{a}}(85.7)$ & $67(89.3)$ & n.s \\
\hline $\mathrm{LMWH}+$ antiplatelets drug during hospitalization $\mathrm{n}(\%)$ & 49 (18.6) & $34(17.8)$ & $15(20)$ & n.s \\
\hline Death during hospitalization (\%) & $76(28.8)$ & $46(24.3)$ & $30(40)$ & 0.016 \\
\hline \multicolumn{5}{|l|}{ COVID-19 treatment ${ }^{\mathrm{d}}$} \\
\hline Hydroxychloroquine & $43(16.3)$ & $25(13.2)$ & $18(24)$ & 0.042 \\
\hline Ritonavir/lopinavir & $37(14.1)$ & $17(9.0)$ & $20(26.7)$ & 0.001 \\
\hline Antibiotics & $152(57.6)$ & $105(55.6)$ & $47(62.7)$ & n.s \\
\hline Steroids & $54(20.5)$ & $37(19.6)$ & $17(22.7)$ & n.s \\
\hline
\end{tabular}

Categorical variables are expressed as number and percentage; continuous variables are expressed as mean ( \pm standard deviation) or median (IQR)

${ }^{\mathrm{a}} \mathrm{NMCR}=$ non major clinically relevant; data missing for 3 patients

${ }^{\mathrm{b}} 17$ DOACs ( 2 in association with antiplatelets), 19 Vitamin $\mathrm{K}$ antagonists (3 in association with antiplatelets)

${ }^{\mathrm{c}} 44$ aspirin, 8 clopidogrel and 7 both

${ }^{\mathrm{d}}$ Some data missing 
Table 2 LMWH treatment regimen by care setting

\begin{tabular}{lcclrl}
\hline Patients & $\begin{array}{l}\text { All } \\
\mathrm{n}=261\end{array}$ & $\begin{array}{l}\text { Medical wards } \\
\mathrm{n}=186\end{array}$ & OR (95\% CI) & $\begin{array}{l}\text { ICU } \\
\mathrm{n}=75\end{array}$ & OR (95\% CI) \\
\hline No prophylaxis & $32(12.3)$ & $24(12.9)$ & Ref & $8(10.7)$ & Ref \\
Prophylactic doses n (\%) & $197(75.5)$ & $147(79.0)$ & $56.4(28.4-111.9)$ & $50(66.7)$ & $21.7(8.6-54.5)$ \\
Intermediate doses n (\%) & $17(6.5)$ & $6(3.2)$ & $0.2(0.02-0.5)$ & $11(14.6)$ & $1.4(0.5-3.9)$ \\
Therapeutic doses n (\%) & $15(5.7)$ & $9(4.9)$ & $0.3(0.2-0.8)$ & $6(8.0)$ & $0.7(0.2-2.2)$ \\
\hline
\end{tabular}

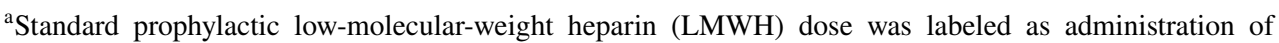
enoxaparin $4000 \mathrm{IU}$ once daily

${ }^{\mathrm{b}}$ Intermediate doses as $60 \mathrm{mg}$ subcutaneously once-daily or 4000 IU twice daily

${ }^{\mathrm{c}}$ Therapeutic doses as administration of $100 \mathrm{U} / \mathrm{Kg}$ twice daily
3-4 units, the remaining seven received more than $4 \mathrm{RBC}$ units. Univariate analysis showed a significant higher odd to be transfused in patients treated with prophylactic LMWH than those who did not receive any prophylaxis.

As regards the number of RBC transfused by therapeutic regimen, seven out of 19 patients treated with prophylactic $(36.8 \%)$ and six out of $12(50 \%)$ with intermediate or therapeutic doses received more than $2 \mathrm{RBC}$ units.

At univariate analysis, patients treated with intermediate or therapeutic doses of LMWH were more often transfused than those who were not administered with LMWH (Table 3). However, these data need to be cautiously interpreted, because of the small sample size.

Hemoglobin ( $\mathrm{Hb})$ at admission was significantly lower in those who were transfused than in those who did not need transfusion (Mann Whitney $\mathrm{U}(p<0.001)$ (Table 3$)$. $\mathrm{Hb}$ levels at admission to the hospital were inversely correlated with the number of RBC units transfused (Pearson $p<0.001$ ), suggesting a close relationship with the odd of having an allogenic transfusion.

\section{Factors affecting mortality}

In-hospital mortality occurred in $76(28.8 \%)$ patients, 46 (24.3\%) of whom were admitted to medical wards (Fig. 1). The median fatalities age was 80.5 years (IQR 14.8).

Furthermore, $\mathrm{Hb}$ levels at admittance were significantly lower in patients who died during hospitalization $(\mathrm{g} / \mathrm{dl}$ 12.3; IQR 2.4 vs. 13.3; IQR 2.8; Mann-Whitney U-test; $p=0.001)$.

After the exclusion of patients treated by LMWH intermediate or therapeutic doses $(n=32)$, the logistic regression showed that prophylactic doses significantly and independently reduced mortality (OR $0.31,95 \%$ CI $0.13-0.85$ ).
Table 3 Clinical Features of COVID-19 patients: differences between transfused and nontransfused patients

\begin{tabular}{llll}
\hline & $\begin{array}{l}\text { Not transfused } \\
\mathrm{n}=225\end{array}$ & $\begin{array}{l}\text { Transfused } \\
\mathrm{n}=39\end{array}$ & $\mathrm{p}$ \\
\hline Sex, male/female & $131 / 94$ & $18 / 21$ & $\mathrm{n} . \mathrm{s}$ \\
Age years, median (IQR) & $72(22)$ & $75(16)$ & $\mathrm{n} . \mathrm{s}$ \\
Smoking $\mathrm{n}(\%)$ & $19(8.4)$ & $2(5.1)$ & $\mathrm{n} . \mathrm{s}$ \\
Hb at admission g/dl, median (IQR) & $13.3(2.4)$ & $10.6(3)$ & $<0.001$ \\
Diabetes, $\mathrm{n}(\%)$ & $49(21.8)$ & $7(18)$ & $\mathrm{n} . \mathrm{s}$ \\
Hypertension, $\mathrm{n}(\%)$ & $117(52)$ & $6(15.4)$ & $<0.001$ \\
History if cancer and/or active cancer n (\%) & $37(16.4)$ & $7(18)$ & $\mathrm{n} . \mathrm{s}$ \\
Cerebrovascular disease, $\mathrm{n}(\%)$ & $16(7.1)$ & $3(7.7)$ & $\mathrm{n} . \mathrm{s}$ \\
Cardiovascular disease, $\mathrm{n}(\%)$ & $51(22.7)$ & $13(33.3)$ & $\mathrm{n} . \mathrm{s}$ \\
Chronic kidney disease, $\mathrm{n}(\%)$ & $28(12.4)$ & $6(15.4)$ & $\mathrm{n} . \mathrm{s}$ \\
Chronic obstructive pulmonary disease, $\mathrm{n}(\%)$ & $24(10.7)$ & $4(10.3)$ & $\mathrm{n} . \mathrm{s}$ \\
No prophylaxis & $25(11.1)$ & $7(18)$ & $<0.001$ \\
LMWH prophylactic doses & $178(79.1)$ & $19(48.7)$ & \\
LMWH intermediate doses n (\%) & $9(4.6)$ & $8(25)$ & \\
LMWH Therapeutic doses n (\%) & $10(4.4)$ & $5(12.8)$ & \\
LMWH+ antiplatelets drug n (\%) & $42(18.7)$ & $7(17.9)$ & $\mathrm{n} . \mathrm{s}$ \\
Major or NMCR haemorrhage $\mathrm{n}(\%)$ & $12(5.3)$ & $1(2.6)$ & $\mathrm{n} . \mathrm{s}$ \\
\hline
\end{tabular}

NMCR non major clinically relevant 


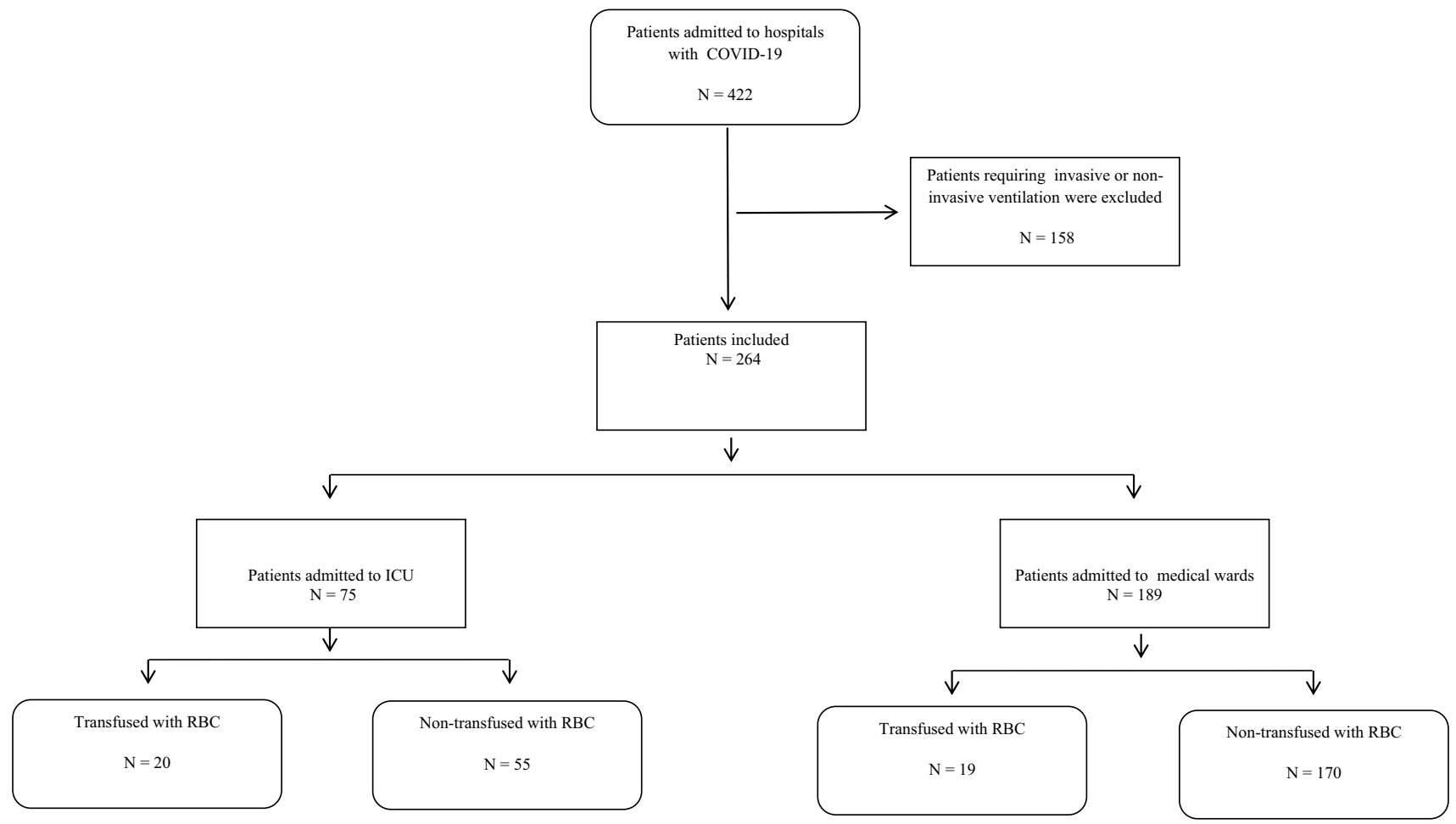

Fig. 1 Diagram describing the entire cohort of patients

Table 4 Logistic regression - factors affecting mortality

\begin{tabular}{llll}
\hline Variable & $\mathrm{p}$ & $\mathrm{OR}$ & $95 \% \mathrm{CI}$ \\
\hline Age & 0.00 & 1.09 & $1.05-1.14$ \\
LMWH prophylaxis & 0.02 & 0.31 & $0.13-0.85$ \\
ICU access & 0.24 & 2.46 & $1.13-5.37$ \\
CKD & 0.06 & 3.58 & $1.65-10.90$ \\
Number of transfusions & 0.04 & 1.32 & $1.01-1.72$ \\
\hline
\end{tabular}

Multivariate analysis was adjusted for age, sex, comorbidities, ICU admission, medical therapy, number of red blood cell units and hemoglobin values at admission

$C K D$ chronic kidney disease, $R B C$ red blood cells, $I C U$ intensive care unit

Furthermore, age, ICU access, CKD, and the number of transfused RBC units significantly predicted mortality (Table 4).

\section{Discussion}

The novelty of the present study is that the observation is restricted to COVID-19 patients who did not require invasive or non-invasive ventilation. In our academic hospitals, patients were mostly treated with prophylactic doses of LMWH, whereas intermediate or therapeutic doses were used only in a small group of patients $(n=32,12.3 \%)$. This means that most clinicians strictly adhere to the current international recommendations, based on observational data or information obtained in similar setting of hospitalized patients $[9,10,14,19-21]$.

Conflicting results have been so far published on the effectiveness of prophylactic doses of LMWH in reducing mortality in COVID-19 patients. Italian data obtained in 2,574 patients showed that heparins reduce fatalities by $40 \%$ (HR $0.60 ; 95 \%$ CI 0.49 to 0.74 ); in that study the prophylactic doses were more effective in lowering mortality than the therapeutic ones (60\% vs 35\%) [9]. We confirm and extend these findings, as we find that prophylaxis with LMWH reduces by almost $70 \%$ mortality in patients with mild/moderate disease, regardless of comorbidities, sex and age (Table 3).

On the other hand, a recent systematic review and meta-analysis of eight retrospective observational studies $(n=2946$ patients) did not find a reduction of mortality in patients receiving prophylactic doses of heparin [22]. These authors conclude that current evidence is not sufficient to support the role of prophylactic doses of heparin in reducing fatalities among COVID-19 patients (OR 0.96, 95\% CI 0.80-1.14). However, it is noteworthy that in the sub-group with moderate symptoms, heparin prophylaxis reduced mortality.

It is plausible that these conflicting results may depend on patients' heterogeneity, their co-morbidities and the 
requirement of invasive or non-invasive ventilation. In this context, viscoelastic tests might be helpful in rapidly identifying patients with severe COVID-19 [23] and in monitoring coagulation and LMWH effect [24]. From present data, we cannot draw conclusions about intermediate or therapeutic doses in terms of efficacy and safety, as they were used in a small group of patients.

Marongiu et al. have hypothesized that pulmonary thrombosis may complicate the course of 2019-nCoV pneumonia, via complement and cytokine release and a blood coagulation activation with vascular microthrombosis $[25,26]$. Therefore, it is likely that LMWH might reduce fatalities by lowering the risk of pulmonary microthrombosis. In this setting, heparins can have also an anti-inflammatory effect, as one of the hypothesized mechanisms of action is their binding to pro-inflammatory cytokines, leading to a reduction of cytokines levels [27].

In agreement with findings from other series, our study shows that ICU access $[28,29]$ and CKD predict mortality [30, 31]. Interestingly, transfusion need is not higher in patients administered with prophylactic LMWH doses, therefore confirming that this scheme is safe. However, number of transfusions are significantly and independently associated with mortality (OR 1.32, 95\% CI 1.01-1.72), as previously reported in other studies [32,33]. Therefore, we agree with those who suggest to use restrictive thresholds for RBC in COVID-19 patients, although clinicians may have the temptation to choose intervention over caution in critically-ill patients [34].

\section{Conclusions}

Present data show that COVID-19 patients who do not require invasive or non -invasive ventilation benefit from prophylactic doses of LMWH. This information strengthens the role of LMWH in all hospitalized patients with infection from SARS-CoV2.

\begin{abstract}
Author contributions EG, MMar designed the study, analysed data and wrote the draft; RP, GC, LM, LD, GLT, AO and MI, collected and interpreted data; DaC, DoC, MTS, MMas and AdL collected and managed data; EG, RP, MMar revised the article critically for important intellectual content. All authors critically revised the article and approved the final version.
\end{abstract}

Funding The study was funded by Italian Ministry of Health (RC2020).

Data availability The data presented in this study are available on request from the corresponding author.

\section{Compliance with ethical standards}

Conflict of interest The authors declare no conflict of interest.

\section{References}

1. Bialek S, Boundy E, Bowen V et al (2020) Severe outcomes among patients with coronavirus disease 2019 (COVID-19)United States, February 12-March 16, 2020. MMWR Morb Mortal Wkly Rep 69:343-346. https://doi.org/10.15585/mmwr. mm6912e 2

2. Price-Haywood EG, Burton J, Fort D, Seoane L (2020) Hospitalization and mortality among black patients and white patients with Covid-19. N Engl J Med 382:2534-2543. https://doi.org/10.1056/ nejmsa2011686

3. Porfidia A, Pola R (2020) Venous thromboembolism in COVID19 patients. J Thromb Haemost 18:1516-1517. https://doi.org/10. $1111 /$ jth. 14842

4. Wichmann D, Sperhake JP, Lütgehetmann M et al (2020) Autopsy findings and venous thromboembolism in patients with COVID19: a prospective cohort study. Ann Intern Med 173:268-277. https://doi.org/10.7326/M20-2003

5. Zhai Z, Li C, Chen Y et al (2020) Prevention and treatment of venous thromboembolism associated with coronavirus disease 2019 infection: a consensus statement before guidelines. Thromb Haemost 120:937-948. https://doi.org/10.1055/s-0040-1710019

6. World Health Organization (2020) Clinical management of severe acute respiratory infection when novel coronavirus (2019-nCoV) infection is suspected: interim guidance, 28 January 2020 . World Health Organization. https://apps.who.int/iris/handle/10665/ 330893

7. Malas MB, Naazie IN, Elsayed N et al (2020) Thromboembolism risk of COVID-19 is high and associated with a higher risk of mortality: a systematic review and meta-analysis. EClinicalMedicine. https://doi.org/10.1016/j.eclinm.2020.100639

8. Hasan SS, Radford S, Kow CS, Zaidi STR (2020) Venous thromboembolism in critically ill COVID-19 patients receiving prophylactic or therapeutic anticoagulation: a systematic review and meta-analysis. J Thromb Thrombolysis. https://doi.org/10.1007/ s11239-020-02235-Z

9. Di Castelnuovo AF, Costanzo S, Iacoviello L (2021) Heparin in COVID-19 patients is associated with reduced in-hospital mortality: the multicentre Italian CORIST Study. Thromb Haemost. https://doi.org/10.1055/a-1347-6070

10. Billett HH, Reyes-Gil M, Szymanski J et al (2020) Anticoagulation in COVID-19: effect of enoxaparin, heparin, and apixaban on mortality. Thromb Haemost 120:1691-1699. https://doi.org/ 10.1055/s-0040-1720978

11. Piazza G, Campia U, Hurwitz S et al (2020) Registry of arterial and venous thromboembolic complications in patients with COVID-19. J Am Coll Cardiol 76:2060-2072. https://doi.org/10. 1016/j.jacc.2020.08.070

12. Nadkarni GN, Lala A, Bagiella E, Chang HL, Moreno PR, Pujadas E, Arvind V, Bose S, Charney AW, Chen MD, Cordon-Cardo C, Dunn AS, Farkouh ME, Glicksberg BS, Kia A, Kohli-Seth R, Levin MA, Timsina P, Zhao S, Fayad ZA, Fuster V (2020) Anticoagulation, Bleeding, Mortality, and Pathology in Hospitalized Patients With COVID-19. J Am Coll Cardiol 76:1815-1826

13. Tremblay D, Van Gerwen M, Alsen M et al (2020) Impact of anticoagulation prior to COVID-19 infection: a propensity scorematched cohort study. Blood 136:144-147. https://doi.org/10. 1182/BLOOD.2020006941 
14. Shen L, Qiu L, Liu D et al (2021) The association of low molecular weight heparin use and in-hospital mortality among patients hospitalized with COVID-19. Cardiovasc Drugs Ther. https://doi. org/10.1007/s 10557-020-07133-3

15. Mattioli M, Benfaremo D, Mancini M et al (2020) Safety of intermediate dose of low molecular weight heparin in COVID19 patients. J Thromb Thrombolysis. https://doi.org/10.1007/ s11239-020-02243-z

16. Grandone E, Pesavento R, Tiscia G et al (2021) Mortality and transfusion requirements in COVID-19 hospitalized Italian patients according to severity of the disease. J Clin Med. https:// doi.org/10.3390/jcm10020242

17. Schulman S, Kearon C (2005) Definition of major bleeding in clinical investigations of antihemostatic medicinal products in non-surgical patients. J Thromb Haemost. https://doi.org/10. 1111/j.1538-7836.2005.01204.x

18. Granger CB, Alexander JH, McMurray JJV et al (2011) Apixaban versus warfarin in patients with atrial fibrillation. N Engl J Med. https://doi.org/10.1056/nejmoa1107039

19. Flumignan RLG, de Sa Tinôco JD, Pascoal PIF et al (2020) Prophylactic anticoagulants for people hospitalised with COVID-19. Cochrane Database Syst Rev. https://doi.org/10.1002/14651858. CD013739

20. Cuker A, Tseng EK, Nieuwlaat R et al (2021) American Society of Hematology 2021 guidelines on the use of anticoagulation for thromboprophylaxis inpatients with COVID-19. Blood Adv 5:872-888

21. Cuker A, Tseng EK, Nieuwlaat R et al (2021) American Society of Hematology 2021 guidelines on the use of anticoagulation for thromboprophylaxis in patients with COVID-19. Blood Adv 5:12-14. https://doi.org/10.1182/bloodadvances.2020003763

22. Abdel-Maboud M, Menshawy A, Elgebaly A et al (2020) Should we consider heparin prophylaxis in COVID-19 patients? A systematic review and meta-analysis. J Thromb Thrombolysis. https://doi.org/10.1007/s11239-020-02253-x

23. Raval JS, Burnett AE, Rollins-Raval MA et al (2020) Viscoelastic testing in COVID-19: a possible screening tool for severe disease? Transfusion 60:1131-1132. https://doi.org/10.1111/trf.15847

24. Stattin K, Lipcsey M, Andersson H et al (2020) Inadequate prophylactic effect of low-molecular weight heparin in critically ill COVID-19 patients. J Crit Care 60:249-252. https://doi.org/10. 1016/j.jcrc.2020.08.026

25. Marongiu F, Grandone E, Barcellona D (2020) Pulmonary thrombosis in 2019-nCoV pneumonia? J Thromb Haemost 18:15111513. https://doi.org/10.1111/jth.14818
26. Becker RC (2020) COVID-19 update: Covid-19-associated coagulopathy. J Thromb Thrombolysis. https://doi.org/10.1007/ s11239-020-02134-3

27. Li JP, Vlodavsky I (2009) Heparin, heparan sulfate and heparanase in inflammatory reactions. Thromb Haemost 102:823-828. https:// doi.org/10.1160/TH09-02-0091

28. Gupta S, Hayek SS, Wang W et al (2020) Factors associated with death in critically ill patients with coronavirus disease 2019 in the US. JAMA Intern Med 180:1436-1446. https://doi.org/10.1001/ jamainternmed.2020.3596

29. Yang X, Yu Y, Xu J et al (2020) Clinical course and outcomes of critically ill patients with SARS-CoV-2 pneumonia in Wuhan, China: a single-centered, retrospective, observational study. Lancet Respir Med 8:475-481. https://doi.org/10.1016/S22132600(20)30079-5

30. Ozturk S, Turgutalp K, Arici M et al (2020) Mortality analysis of COVID-19 infection in chronic kidney disease, haemodialysis and renal transplant patients compared with patients without kidney disease: a nationwide analysis from Turkey. Nephrol Dial Transplant. https://doi.org/10.1093/ndt/gfaa271

31. Gansevoort RT, Hilbrands LB (2020) CKD is a key risk factor for COVID-19 mortality. Nat Rev Nephrol. https://doi.org/10.1038/ s41581-020-00349-4

32. Muady GF, Bitterman H, Laor A et al (2016) Hemoglobin levels and blood transfusion in patients with sepsis in internal medicine departments. BMC Infect Dis. https://doi.org/10.1186/ s12879-016-1882-7

33. Rim JH, Lee SA, Han CH, Yoo J (2020) Transfusion demand in COVID-19 patients from the Korean population: a nationwide study in South Korea. Br J Haematol 190:e322-e328. https://doi. org/10.1111/bjh. 17030

34. Chowdhury JF, Moores LK, Connors JM (2020) Anticoagulation in hospitalized patients with Covid-19. N Engl J Med 383:16751678. https://doi.org/10.1056/nejmclde2028217

Publisher's Note Springer Nature remains neutral with regard to jurisdictional claims in published maps and institutional affiliations. 